Low team morale and high staff turnover? Christine MacLeavy` reveals the true power of good communication.
I 'm sure you've heard the old cliché 'people are a company's best asset'. In many ways it is true. You've probably also heard the saying 'a chain is only as strong as its weakest link'. Again very true. But have you heard this one? 'You only ever get the staff you deserve.'

Unless you have been on the receiving end of some business coaching you may not realise just how much a business (any business - and that includes dentistry) is a reflection of its owner. Some dental principals want to control everything and then wonder why their team never wants to take the initiative.

This article is all about team members, those special people who drive the practice each and every day. Those dental nurses, receptionists, hygienists and therapists who make a valuable contribution to the dentist's livelihood, without whom he or she wouldn't be where they are today.

\section{To the dentist/principal}

Do you realise that your team members really are your greatest assets? Do you treat them as such? Does your team fire on all cylinders? Is your practice feeling the full effects of their true potential? Do you refer to the people that work for you as your 'staff' or worse still a 'human resource'? They are neither; they are human beings who deserve to be respected, treated fairly and with dignity.

Neglecting the team has to be one of the great tragedies of modern day business. A recent Australian survey revealed that some $85 \%$ of all workers reported being bullied at work. Just think of the effects on productivity, motivation, and absence. Especially if the bully ... is you?

\section{So if you have a dream team or are} part of a dream team read no further With compulsory registration, dental nurses, like the rest of the team, will have to take full responsibility for their actions and be accountable to the GDC. The impact of this may make many dental nurses think long and hard about their careers in dentistry. Many unqualified dental nurses who have been working part time may not find the idea of going through a 'grandparenting' scheme, or back into education at all, that appealing. Dental nurses may simply choose to leave the profession. It is well known that high staff turnover and low staff morale continue to plague dentistry.

In modern dental practice the dentist must learn to be a leader. Learn to delegate. The key to building a successful practice is almost never doing more; it's hiring and supporting great people.

So, look after your team members and they will look after you!

At the heart of good teamwork is excellent communication not just between dentists and their teams but between team members as well.

\section{Rapport}

Excellent communication begins with rapport. Rapport stems from emotional attunement, from the capacity for empathy. Because we as a profession are quite good at empathising with our patients, we feel that we are good communicators. However, when it comes to communication within the team, it may be another matter.

There is a saying in NLP (Neuro-Linguistic Programming) that the meaning of the communication is the response you get. This means that the response you get from a person may be different from the one you were expecting or wanting; however, there are no failures in communication, only responses and feedback. If you are not getting the result you want, change what you are doing. Take responsibility for the communication and pay attention to the feedback. Do not assume that because the other person has not understood correctly that it is their fault. It may be the way you have communicated to them.

NLP began by Richard Bandler and John Grinder studying the best communicators and has evolved into the systematic study of human communication. Therefore no article on communication would be complete without some reference to NLP.

Rapport is one of the basic pillars of NLP. Rapport refers to the quality of a relationship that results in mutual trust and responsiveness. You gain rapport by understanding and 
Four vital keys to listening

1. Listen attentively, completely and without interrupting.

2. Pause before replying. Deliberately wait for 3-4 seconds, in order to allow what the other person has said to 'soak in' and to fully understand. When you do reply it will be more intelligent than if you began speaking immediately. Demonstrate that you are giving careful consideration to what they said - this is extremely flattering - and it convinces them that what they have to say is important and meaningful to you. If the other person has merely stopped to gather their thoughts, you avoid the possibility of interrupting them. You will come across as a graceful, elegant and classy conversationalist. Active listening is surprisingly difficult and requires practice if you are to master it properly. Steven Covey, author of The seven habits of highly effective people' stated that 'most people do not listen with the intent to understand, they listen with the intent to reply.'

3. Question for clarification. Never assume that you fully understand what the other person has said, or the key points they have made. Most people say things that are only half formed or things come out in a way they didn't really mean. When you ask a question you give them a chance to rephrase and express it in a different way. Often the second statement may be very different from what you thought you heard the first time. Questions may be closed or open. Closed questions are designed to close possibilities and can be answered by a simple 'yes' or 'no'. Open questions begin with 'what', 'why', 'when', 'where' and 'how'.

4. Feed back to the other person by paraphrasing in your own words. The ability to paraphrase is a key communication skill and powerful learning skill as well. When the other person finishes speaking say 'Let me make sure I understood you clearly...' or 'What you seem to be saying is...' Paraphrase in your own words. They may say 'No that's not what I meant at all' and go on to explain it differently, or 'Yes, that's right'. respecting the way another person sees the world. It is like speaking their language. Rapport is essential for good communication. If you have rapport others will feel acknowledged and immediately be more responsive. It is possible to build rapport at many levels, but all involve paying attention to and respecting the other person. Rapport can be built instantly and rapport over time builds trust.

Rapport is not manipulation; rapport is not the same as friendship. Being in rapport is mutually enjoyable although it is possible to agree with someone and not be in rapport. It is equally possible to disagree with someone and be totally in rapport.

Regardless of your own beliefs and values you build powerful rapport by respecting and understanding the beliefs and values of others. You do not have to agree with them, only respect what is important to the individual.

Does your team communicate with mutual trust and responsiveness? Does everyone feel acknowledged and respected? If not you may have to work on building rapport. This can be achieved by taking a genuine interest in the other team members, by being curious about who they are and how they think, and by being willing to see the world from their point of view.

\section{Perceptual positions}

Excellent communicators have high levels of empathy with others and are extremely sensitive to their feelings. They can put themselves in another person's position instead of ignoring or downplaying their feelings or concerns; they imagine how they would feel in that situation.

In NLP a technique known as 'perceptual positions' helps with understanding another person's position without necessarily agreeing with it. The solution to problems within the team or between member(s) of the team and 
the dentist can be successfully dealt with using perceptual positions. It is possible using this technique to take a mental step outside your own feelings about a problem/situation and step into the other person's perspective, to try to think the way that they think. A third perceptual position may also be considered. This is the perspective of the impartial observer who may offer a more detached way of seeing things. The perceptual positions technique is excellent for staff meetings, analysing practice problems, relationship issues, and for viewing options or changes from team members' and patients' points of view.

Team members need to feel that you understand them and are making a genuine effort to empathise - this makes them much more open to you when you want their cooperation at a later time. Perceptual positions can help understand the other person's 'map of the world'.

\section{Listening}

Listening skills are essential for successful communication with other people, especially other team members. Listening builds trust and trust is the basis of all relationships.

\section{Incongruence}

Humans are sensitive to incongruence, between words, the message and the person. We always look for contradictions as a way of protecting ourselves from being misled or deceived.

There are actually three ingredients to any message you communicate. According to a Harvard University study, ${ }^{3}$ the words you use only account for $7 \%$ of the message, whereas tone of voice and facial expressions account for $38 \%$ of the message. Body language, the way you sit, stand, walk, talk and move account for $55 \%$ of the message. People always believe the dominant part of the message eg if you are sitting with arms folded, turned away, looking up towards the ceiling, it is very hard to convince someone that you like or care about them no matter what you say.

It is only when your words, tone of voice and body language are synchronised and in harmony that a person believes totally the message you are sending.

Because your team can make or break your business, you need to set up mechanisms to foster team spirit and a culture that will be set out in your Mission Statement. As well as regular staff meetings to discuss practice issues, establish weekly 'WIFLE' sessions (What I Feel Like Expressing) in which team members have uninterrupted time to speak their thoughts without fear of recrimination. This is a very powerful safety valve that has been introduced to thousands of businesses around the world.

A successful team communicates with each other honestly and regularly. However, if strong leadership doesn't back up the team, the result will be like having a supertanker without a rudder. Strong leadership is crucial. By strong leader I mean a director not a dictator.

'Imagine the benefits for work of being skilled in basic emotional competencies - being attuned to the feelings of those we deal with, being able to handle disagreements so they don't escalate, having the ability to get into flow states while working.

'Leadership is not domination but the art of persuading people to work towards a common goal. ${ }^{2}$

A good leader gets involved with the team members, they communicate clearly what needs to be done, but rather than dictate how to do it, where to do it or when to do it, they explain, listen, encourage, support and facilitate and then they trust.

1. Covey. S. The seven habits of highly effective people. London: Simon \& Schuster, 2004.

2. Goleman D. Emotional intelligence. London: Bloomsbury, 1996.

3. Mehrabian A. Silent messages: implicit communication of emotions and attitudes. Belmont CA: Wadsworth, 1981.

\section{Further reading}

O'Connor J, Seymour J. Introducing NLP: psychological skills for understanding and influencing people. London: Mandala, 1990.

Christine would be happy to receive feedback or answer queries and can be contacted via email onchris@macleavy.freeserve.co.uk.

'Christine has been a Dental Therapist for 27 years and treats children and adults with special needs. She also teaches part time at the Eastman Dental Hospital in the School for Dental Hygiene and Dental Therapy. She has studied Neuro-Linguistic Programming (NLP) with Paul McKenna Training, gained a Diploma in Performance Coaching, recently completed a Postgraduate Diploma in Hypnosis Applied to Dentistry, has completed training in Thought Field Therapy and is currently undertaking her NLP Master Practitioner! 